\title{
Research on the Development Strategy of Sports Industry Based on Innovation Mechanism
}

\author{
Jin Qiang ${ }^{1, a}$ \\ ${ }^{1}$ Tonghua normal university sports institute, Tonghua 134000,China \\ a Jinqiang2013@yeah.net
}

Keywords: Innovation mechanism, Sports industry, Development strategy, Interval test,

\begin{abstract}
With the development of economy, sports industry has become one of the global hot industry today, also is a new industry with fierce competition, open space and higher profit, etc. In social economy, its proportion has shown an increasing trend. How to plan sports science to be scientifically developed is the urgent problem needed to solve in the field. This paper firstly analyzes the current situation of sports industry development, and analyzes the characteristics of the development of innovation mechanism industry. On this basic, based on normality assumption environment, it builds the model of optimizing industrial development strategy under the innovation mechanism. Scientific development strategic decision of sports industry provides practice guideline to a certain extent for the healthy development of the sports industry.
\end{abstract}

\section{Introduction}

Since the reform and opening up, with our country economic constantly developed and boomed, along with the globalization of the international economy, our people's democracy and freedom advocated also has obtained their own development space. According to the current situation of sports development in developed countries, generally speaking, sports industry has its own law of development [1]. The main components and influence factors of sports industries include sports industry consumer, sports industry producer, sports industry products and market demand factors, etc $[2,3]$.

\section{Development advantages of innovation mechanism sports industry}

If an enterprise wants to walk in the forefront of the times, it can not do without innovation mechanism theoretical thinking even for a moment, and there's not a moment to stop mechanism innovation. The innovation mechanism enterprises need to develop their own enterprises to continuously update in the enterprise product quality [4].

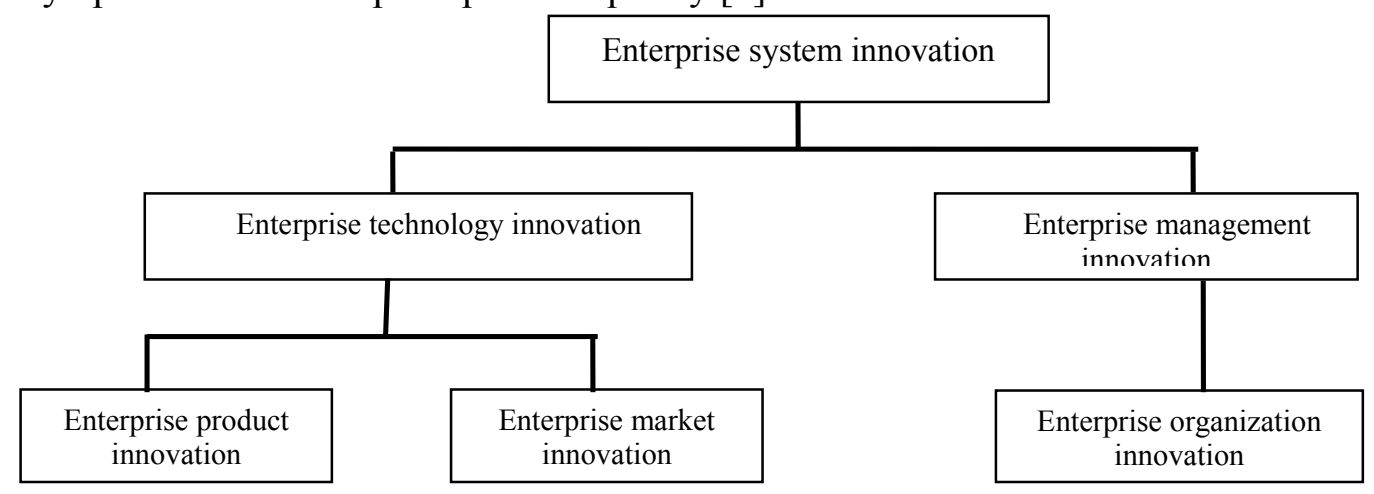

Figure 1. The connotation of innovated mechanism industry 
Figure 1 shows that innovation mechanism firstly needs to carry on the innovation of enterprise system. On the basis of the innovation of enterprise management and technology, system innovation is the core and the premise of industrial innovation [5]. Without scientific system innovation, every innovation is empty. Enterprise management innovation needs to be based on organizational innovation. Without system innovation it is difficult to construct the whole enterprise management innovation mechanism. So it needs to make organization innovation based on enterprise innovation mechanism to strengthen the foundation of mechanism innovation.

The development of sports industry innovation mechanism can set a confidence interval. Through the reliability of sports industry innovation mechanism's confidence interval, it excavates the development of sports industry innovation mechanism. Assuming the development confidence interval of sports industry innovation mechanism is $\beta_{2}$. According to the estimated value $\hat{\beta}_{2}$ of the confidence interval of the whole industry $\beta_{2}$, it analyzes the development advantage of sports industry innovation mechanism. The regression reliability of factor true value can meet the demand of the whole sports industry development. So $\frac{\hat{\beta}_{2}-\beta_{2}}{\sqrt{\frac{\hat{\sigma}^{2}}{\sum x_{2 i}{ }^{2}}}}$ is subject to the market economy demand $\mathrm{t}$ distribution of freedom $(n-2)$. This paper uses $t$ distribution to construct the confidence interval of the sports industry innovation mechanism development $\beta_{2}$.

In the industrial development zone, for the confidence interval $\beta_{2}$ of the development of sports industry innovative mechanism, its probability is adapt to $(1-\alpha)$. When $0<\alpha<1$, the reliability of sports industry innovation mechanism has stringer requirements. $\alpha$ is significant level. $\alpha$ is smaller which represents the significance of the development of sports industry innovation mechanism is stronger. It makes the probability between the two critical point is equal to $(1-\alpha)$. Trough the innovation mechanism, it can construct the development life cycle model of sports industry to carry out more scientific development of the sports industry.

\section{Optimizing the model of sports industry development strategy under the innovation mechanism}

Under the innovation mechanism, optimizing the model building of sports industry development strategy needs to consider the existing multivariate optimization. At the time of determining industrial development ownership, it is adhere to the investment and profit coordination principle. It takes the government funding, the introduction of foreign capital, and development jointing with venture measures to add new facilities to fill the blank of government financing, so as to improve the optimization index social financing means of optimizing sports industry development[6]. At the same time, it makes full use of the advantage of optimizing sports industry development strategy resource. The development preliminary model is as shown in Figure 2. 


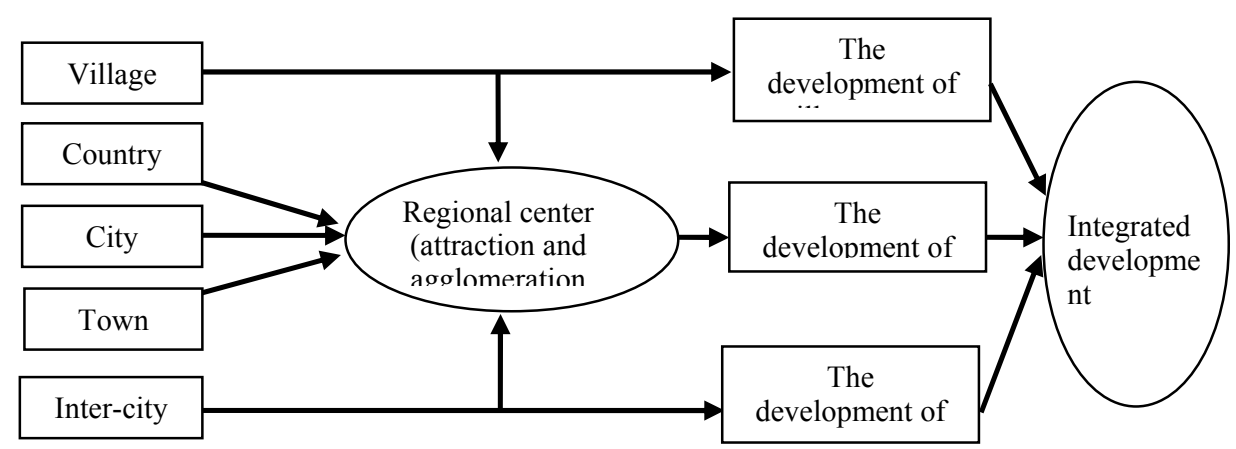

Figure 2. Optimizing the strategy resources of sports industry development under the innovation mechanism

Figure 2 shows that under the innovation mechanism, optimizing the strategy resources of sports industry development needs to consider the integrated development of village, town and city, and pays attention to the relationship among the three. Eventually, it forms the industrial chain with resources sharing. Among the confidence interval of $\beta_{2}$, the confidence interval of $100(1-\alpha) \%$ is as shown below.

$$
\left.\left.\operatorname{Pr}\left[\hat{\beta}_{1}-t_{\frac{\alpha}{2}} \hat{S}_{\hat{\beta}_{1}}\right)<\beta_{1}<\hat{\beta}_{1}+t_{\frac{\alpha}{2}} \hat{S}_{\hat{\beta}_{1}}\right)\right]=1-\alpha
$$

In formula (1),

$$
\hat{S}_{\hat{\beta}_{1}}=\hat{\sigma} \sqrt{\frac{\sum X_{2 i}{ }^{2}}{n \sum x_{2 i}{ }^{2}}}
$$

Formula (2) denotes the standard error of $\hat{\beta}_{1}$. The combination of the three does the coordination of the three and uses funds. In the actual operation process, the three need to provide public services to establish a long-term partnership for the public or private sector. The relationship is generally based on contract or agreement. It shares benefits and risks. Through the relation between the three cooperation, it constructs competitive relationship, so as to exert the operation superiority of this mode. Due to under the normality assumption of $u_{i}$, the variable $\chi^{2}=(n-2) \frac{\hat{\sigma}^{2}}{\sigma^{2}}$ is subject to the $\chi^{2}$ distribution of the market economy required $n-2$, so the $\chi^{2}$ distribution constructs the confidence interval of $\sigma^{2}$ :

$$
\operatorname{Pr}\left(\chi_{1-\alpha / 2}^{2}<\chi^{2}<\chi_{\alpha / 2}^{2}\right)=1-\alpha
$$

Based on the organized enterprises to participate in the bid, it carries on the collection and filing of evaluation information. According to the evaluation target, it makes innovation judgment analysis on evaluation information. Eventually, it forms the evaluation result feedback. Through the analysis of formula (6), it can construct the strategy model of sports industry development under the optimized innovation mechanism. The specific is as shown in Figure 3. 


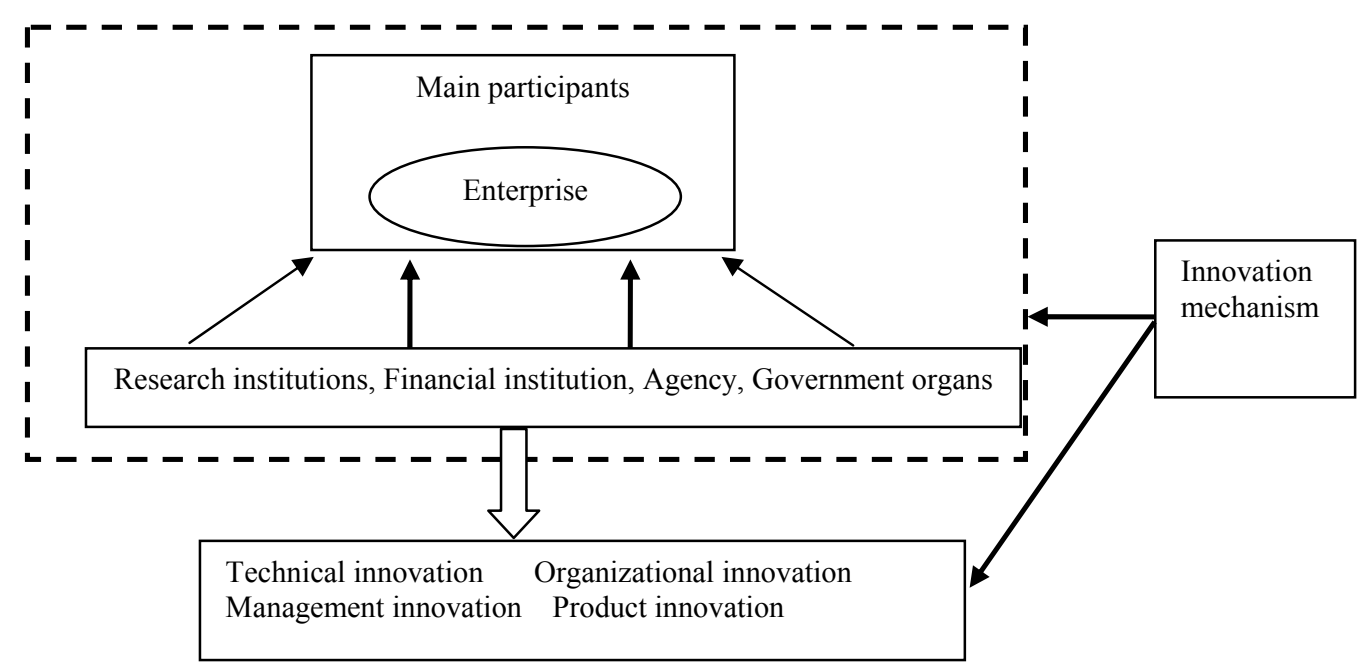

Figure3. Optimizing the development strategy model of sports industry under the innovation

$$
\text { mechanism }
$$

Figure 3 shows that under the innovation mechanism, the development of sports industry firstly makes clear the existing subject of the whole participants, so as to realize other innovation under the innovation mechanism. So:

$$
\operatorname{Pr}\left[(n-2) \frac{\hat{\sigma}^{2}}{\chi_{\alpha / 2}^{2}}<\sigma^{2}<(n-2) \frac{\hat{\sigma}^{2}}{\chi_{1-\alpha / 2}^{2}}\right]=1-\alpha
$$

Under the innovation mechanism, it optimized the development strategy of sports industry. In the actual operation process, social financing investment of the changed model would be much smaller than that of the traditional social financing. The government and relevant departments would participate in guidance to reduce risk. When there was any ambiguity, it would change the operations of the entire sports industry chain. When there was many aspects coordination, it would optimize the operation.

\section{Conclusions}

How to realize the scientific development of modern sports industry, scientific management and operation is one of the problems to be urgently solved for the current sports industry development. The development of sports industry needs to find a development breakthrough in the sports industry reform. It can scientifically and reasonably arrange the resources allocation of sports industry development to play a better social benefit and economic benefit under the existing conditions.

\section{References}

[1] Corrado lo Storto, "A method based on patent analysis for the investigation of technological innovation strategies: The European medical prostheses industry", Technovation, Vol. 26, No. 8, pp. 932-942, 2006.

[2] Qian Shi, Xiaodong Lai, "Identifying the underpin of green and low carbon technology innovation research: A literature review from 1994 to 2010", Technological Forecasting and Social Change, Vol. 27, No. 8, pp. 432-441, 2012.

[3] Zhang Meili, Shi Chunsheng, "Research on Matching Effect of Market-oriented Organizational Innovation and Technological Innovation", JDCTA, Vol. 7, No. 1, pp. 204 - 212, 2013. 
[4] Silvia Rita Sedita, "Leveraging the intangible cultural heritage: Novelty and innovation through exaptation ", City, Culture and Society, Vol. 3, No. 4, pp. 251-259, 2012.

[5] Yuan Dan, "Research on the Model of Sports Industry Competitiveness Based on Factor Analysis and Principal Component Analysis", JDCTA, Vol. 7, No. 2, pp. 288 - 296, 2013.

[6] David Doloreux, Saeed Parto, "Regional innovation systems: Current discourse and unresolved issues ", Technology in Society, Vol. 27, No. 2, pp. 133-153, 2005. 